\title{
PENGEMBANGAN KOMPETENSI PEDAGOGIK GURU ANAK GIFTED
}

\author{
Tri Sundari, Babang Robandi, Yuyus Suherman \\ Surel: sundaritri13@gmail.com
}

\begin{abstract}
The purpose of this study is to find and formulate a pedagogical competency development program for gifted teachers suitable for use in Cugenang Gifted School at the elementary school level. In this study, the authors used qualitative, research methods used were qualitative with case studies. The research subject is the principal and class teachers, in qualitative research the main research instruments are the research itself, data collection techniques, namely interviews, observation, documentation studies, and data triangulation. The results of the study are the competencies of teachers of gifted children can be seen from the results of research on gifted teachers who actively support and diligently support actively in the classroom and can be seen in terms of speaking about the competencies of 10 teacher competencies and pedagogical competencies based on research results, we support that gifted teachers have maximally and special ideal with the needs of gifted children.
\end{abstract}

Keywords: Gifted Children, Pedagogic Competencies, Qualitative

\begin{abstract}
ABSTRAK
Tujuan dari penelitian ini adalah mengetahui untuk menemukan dan merumuskan program pengembangan kompetensi pedagogik guru anak gifted yang cocok diterapkan di Cugenang Gifted School tingkat sekolah dasar. Dalam penelitian ini, penulis menggunakan pendekatan kualitatif (qualitative Research), Metode penelitian yang digunakan adalah pendekatan kualitatif dengan studi kasus. subjek penelitiannya adalah kepala sekolah dan guru kelas, Dalam penelitian kualitatif instrumen utama penelitian adalah peneliti itu sendiri, teknik pengumpulan data, yaitu wawancara, observasi, studi dokumentasi, dan triangulasi data. Hasil penelitian adalah kompetensi guru anak berbakat dapat dilihat dari hasil mengajar guru anak berbakat yang cenderung aktif dan rajin aktif berperan di kelas dan dapat dilihat dari segi berbicara secara aspek 10 komptensi guru dan karakteristik kompetensi pedagogik Berdasarkan hasil penelitian, kami menyimpulkan bahwa hasil kompetensi guru anak berbakat telah maksimal dan ideal khusus dengan kebutuhan anak gifted.
\end{abstract}

Kata Kunci: Anak Gifted, Kompetensi Pedagogik, Kualitatif

\section{PENDAHULUAN}

Sejak dilahirkan setiap anak diberikan kelebihan dan kekurangan yang berbeda satu sama lainnya berdasarkan fitrahnya masingmasing. Salah satu kelebihan tersebut adalah anak yang memiliki kecerdasan dan bakat istimewa atau istilahnya anak berbakat. Anak Berbakat yang di adopsi dari definisi USOE (dalam Munandar, 2009, hlm. 23) disepakati bahwa anak berbakat adalah mereka yang oleh orangorang profesional diidentifikasi 

sebagai anak yang mampu mencapai kemampuan-kemampuan yang unggul. Sedangkan definisi anak berbakat yang lain dikemukakan oleh Renzulli (dalam Davis, 2011, hlm. 21) bahwa anak berbakat merupakan suatu interaksi diantara tiga sifat dasar manusia yang menyatuikatkan antara kemampuan umum yang tingkatannya di atas kemampuan rata-rata (IQ>130), komitmen tinggi terhadap tugas-tugas, dan kreativitas yang tinggi. Sehingga anak berbakat perlu dilatih dan dikembangkan segala potensi yang dimilikinya melalui upaya pendidikan

Sistem Pendidikan Nasional mengatur pendidikan bagi anak cerdas dan bakat istimewa, sebagaimana dinyatakan dalam UU No. 20 tahun 2003 Pasal (5) ayat (4) bahwa: "Warga negara yang memiliki kecerdasan dan bakat istimewa berhak memperoleh pendidilan khusus". Selanjutnya dalam pasal (12) ayat (1) poin (b) dan (f) dinyatakan bahwa: "Setiap peserta didik pada setiap satuan pendidikan berhak: mendapatkan layanan pendidikan sesuai bakat, minat dan kemampuannya. Karena peserta didik berbeda-beda dalam bakat, minat, kemampuan, maka implikasinya adalah bahwa perlakuan pendidikan perlu disesuaikan dengan potensi setiap peseta didik. Anak-anak yang memiliki tingkat kecerdasan jauh di atas rata-rata anak normal lainnya memerlukan pendidikan khusus agar bakat atau potensi mereka yang unggul dapat diwujudkan sepenuhnya.

Berdasarkan Peraturan Menteri Pendidikan Nasional Republik Indonesia Nomor 16 Tahun 2007 tentang Standar Kualifikasi Akademik dan Kompetensi Guru Pasal 1 bahwa setiap guru wajib memenuhi standar kualifikasi akademik dan kompetensi guru yang berlaku secara nasional. Berdasarkan Undang-Undang Rebublik Indonesia Nomor 14 Tahun 2005 Pasal 10 ayat 1 tentang Guru dan Dosen bahwa guru wajib memiliki empat kompetensi guru, yaitu: kompetensi pedagogik, kompetensi kepribadian, kompetensi sosial dan kompetensi professional.

Kompetensi guru anak berbakat lebih banyak berkaitan dengan kompetensi pedagogik guru. Kompetensi pedagogik merupakan salah satu kompetensi yang harus dimiliki dan dikuasai oleh seorang guru sebagai tenaga pendidik karena berkaitan dengan mengelola pembelajaran. Dalam undang-undang No. 14 Tahun 2005 tentang Guru dan Dosen disebutkan bahwa kompetensi pedagogik adalah "kemampuan mengelola pembelajaran peserta didik".

Tidak mudah untuk mengelola pembelajaran anak berbakat karena anak berbakat memiliki karakteristik yang berbeda dengan anak lainnya. Namun, meskipun begitu pembelajaran harus tetap terlaksana dengan efektif. Menurut Andini \& Supardi (2018, hlm. 6) berpendapat bahwa kompetensi pedagogik yang 
Tri sundari, Babang Robandi, Yuyus Suherman : Pengembangan ...

dimiliki oleh seorang guru akan mempengaruhi efektivitas pembelajaran. Agar pembelajaran dapat berjalan efektif maka guru harus dapat mengembangkan kompetensi pedagogiknya.

Sebagai guru anak berbakat, maka perlu sekali pengembangan kompetensi pedagogic agar pembelajaran anak berbakat dapat sesuai dengan keberbakatannya. Pengembangan kompetensi pedagogik ini tidak dapat diperoleh secara instan, akan tetapi memerlukan suatu proses dalam upaya belajar terus menerus dan sistematis. Untuk mengatasasi hal tersebut maka alternative pemecahannya adalah dengan menerapkan lesson study. Berdasarkan pemaparan di atas, artikel ini akan membahas faktorfaktor apa yang perlu dipertimbangkan dalam mengembangkan kompetensi pedagogic guru anak berbakat melalui program lesson study.

\section{Anak Berbakat}

Renzulli (dalam Harjaningrum dkk, 2007, hlm. 113) menyatakan bahwa anak bisa dikatakan anak berbakat apabila ia memiliki intelegensia tinggi di atas rata-rata (IQ>130), kreativitas tinggi, serta motivasi dan komitmen kerja yang tinggi. Hal tersebut sejalan dengan pendapat Santrock (2010, hlm. 251) bahwa anak berbakat memiliki kecerdasan di atas rata-rata (biasanya memiliki IQ di atas 130) dan/atau memiliki bakat unggul di beberapa bidang seperti, seni, musik, atau matematika." Moreover, the selection of gifted students is not based only on their intellectual ability but also includes broad components relating to personality, motivation and work ethic which together contribute to the complete picture of talent. (Zhang, 2017, p. 10).

Sedangkan di Indonesia konsep dalam mengidentifikasi siswa berbakat adalah "The Ring Conception" oleh Renzulli. Seorang anak yang hanya memperlihatkan salah satu ciri saja, artinya belum memperlihatkan keberbakatan. Kriteria keberbakatan menurut Renzulli (dalam Munandar, hlm. 2009, hlm. 26) antara lain: kemampuan umum, kreativitas, dan motivasi (pengikatan diri terhadap tugas). Renzulli meyakini bahwa bila faktor ini menyatu dalam diri individu, hasilnya adalah orang yang benar-benar berbakat.

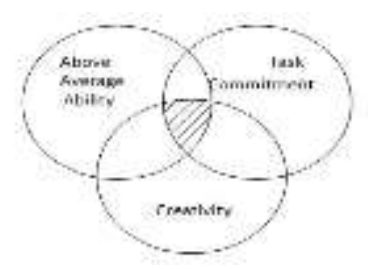

\section{Gambar 1. Konsepsi Renzuli tentang Keberbakatan}

UUSPN No. 2 Tahun 1989, yang disebut anak berbakat adalah "warga negara yang memiliki kemampuan dan kecerdasan luar biasa". Kecerdasan berhubungan dengan perkembangan kemampuan intelektual, sedangkan kemampuan 
luar biasa tidak hanya terbatas pada kemampuan intelektual. Jenis-jenis kemampuan dan kecerdasan luar biasa yang dimaksud dalam batasan ini meliputi: a) kemampuan intelektual umum dan akademik khusus, b) berpikir kreatif-produktif, c) psikososial/kepemimpinan, d) seni/kinestetik, dan e) psikomotor.

Berdasarkan beberapa pengertian di atas dapat diambil kesimpulan bahwa anak berbakat merupakan anak yang memiliki IQ yang lebih unggul dari anak normal lainnya, baik bakat dari segi umum maupun bakat dari segi khusus sehingga anak-anak tersebut membutuhkan layanan pendidikan yang tepat agar segala potensi yang dimilikinya dapat terwujud secara optimal.

\section{Guru Anak Berbakat}

Guru yang baik sangat diperlukan bagi semua anak di sekolah, seperti anak berbakatpun memerlukan guru yang baik. Tidak mudah menjadi guru anak berbakat karena harus peka terhadap kebutuhan-kebutuhan yang diperlukannya. Essential it is that teachers understand children's changing cognitive and affective needs; the importance of teachers' own engagement with both subject matter and the learning process; and the need for students to be exposed to different kinds of teachers at different stages of talent development. (Landvogt, 2001, p. 190).

Menurut Nasoetion (1982, hlm. 65) mengemukakan sejumlah karakteristik yang diperlukan bagi guru anak berbakat, antara lain: a) penguasaan materi yang mantap, b) dengan senang hati menyukai bidangnya, c) menguasai berbagai strategi belajar mengajar, d) mampu mengelola kegiatan belajar mengajar secara individual dan kelompok kecil, e) mengutamakan standar prestasi yang setinggi-tingginya di dalam setiap kesempatan baik untuk siswanya maupun untuk dirinya sendiri, f) suka bergaul dengan anakanak berbakat dengan segala "keresahannya", luwes dalam pendekatan pribadi tetapi tegas dan sistematis di dalam pengaturan kerja.

Menurut Rogers (2014, hlm. 7) ciri-ciri guru bagi anak berbakat antara lain, 1) memiliki tingkat kecerdasan tinggi, 2) memiliki tingkat kejujuran intelektual yang tinggi, 3) memiliki keahlian dalam bidang akademis tertentu, 4) memiliki minat yang tulus dan mneyukai anak berbakat, 5) pengakuan akan pentingnya perkembangan intelektual, 6) keyakinan yang kuat akan perbedaan individu dan indvidualisasi, 7) berketerampilan dan berpengetahuan tinggi tentang bagaimana cara mengajar, 8) mandiri akan pembelajaran sendiri, memiliki rasa cinta akan pengetahuan yang baru dan lebih maju, 9) berkepala dingin dan memiliki emosinal yang dingin.

Berdasarkan uraian di atas, maka dapat disimpulkan bahwa guru adalah pendidik profesional yang memiliki peran penting dalam dunia pendidikan karena bertanggung jawab tehadap seluruh potensi 
Tri sundari, Babang Robandi, Yuyus Suherman : Pengembangan ...

siswanya, baik potensi kogninif, afektif, maupun psikomotornya. Guru untuk anak berbakat harus mampu menyesuaikan dengan diri dengan karakteristik siswanya, agar proses pembelajaran dapat berjalan dengan efektif.

\section{Kompetensi Pedagogik}

Kata kompetensi (Echools dan Shadily, 1984, hlm. 132) berasal dari artinya kecakapan, kemampuan, dan wewenang. Dalam Kamus Besar Bahasa Indonesia, kompetensi diartikan sebagai kewenangan (kekuasaan) untuk menentukan (memutuskan sesuatu). (Departemen P dan K RI, 1990, hlm. 453).

Kata "pedagogik" berasal dari Bahasa Yunani yaitu "paidagogos", yang terdiri atas kata "paidos" dan "agogos" (lead). Maksudnya adalah memimpin anak dalam belajar. Jadi pedagogik secara harfiah berarti pembantu laki-laki pada zaman Yunani Kuno yang pekerjaannya menghantarkan atau membimbing anak majikannya ke sekolah. Sehingga secara kiasan pedagogik merupakan seorang yang ahli yang membimbing anak kearah tujuan hidup tertentu. (Hidayat, 2013, hlm. $1)$.

Jika kedua istilah tersebut digabungkan, maka kompetensi pedagogik guru dapat diartikan sebagai kemampuan atau keahlian seseorang dalam mendidik dan mengajar siswanya. Kompetensi tersebut berkaitan dengan menguasai karakteristik peserta didik dari aspek fisik, moral, spiritual, sosial kultural, emosional, dan intelektual; menguasai teori belajar dan prinsipprinsip pembelajaran yang mendidik; mengembangkan kurikulum yang terikat dengan mata pelajaran yang diampu; menyelenggarakan pembelajaran yang mendidik; memanfaatkan teknologi informasi dan komunikasi untuk kepentingan pembelajaran; memfasilitasi pengembangan potensi peserta didik untuk mengaktualisasikan berbagai potensi yang dimiliki; berkomunikasi secara efektif, empatik, dan santun dengan peserta didik; menyelenggarakan penilaian dan evaluasi proses dan hasil belajar; memanfaatkan hasil penilaian dan evaluasi untuk kepentingan pembelajaran; melakukan tindakan reflektif untuk peningkatan kualitas pendidikan. (Pemerdiknas nomor 16 tahun 2007).

Seorang guru anak berbakat harus dapat menguasai kompetensi pedagogik, karena akan menentukan tingkat keberhasilan dalam suatu proses pembelajaran siswa anak berbakat.

\section{METODE PENELITIAN}

Berdasarkan masalah yang diangkat dalam penelitian ini, metode yang tepat untuk digunakan ini menggunakan pendekatan kualitatif, di mana data yang dikumpulkan diuraikan dalam bentuk deskripsi. Dalam penelitian ini, analisis data meliputi aktivitas yang berkaitan dengan data tentang profil pelaksanaan kompetensi pedagogik guru dalam proses pembelajaran 
anak berbakat di Cugenang Gifted School tingkat sekolah dasar dan kendala dalam pelaksanaan kompetensi pedagogik guru dalam proses pembelajaran anak berbakat di Cugenang Gifted School tingkat sekolah dasar. Lokasi penelitian ini dilaksanakan di Cugenang Gifted School yang berada di Kp. Angkrong RT. 03 / RW. 03 Talaga, Cugenang, Talaga, Kec. Cianjur, Jawa Barat. Dalam penelitian ini, subjek penelitiannya adalah kepala sekolah dan guru kelas. Dalam penelitian kualitatif instrumen utama penelitian adalah peneliti itu sendiri. Teknik pengumpulan data merupakan langkah yang paling utama dalam penelitian, karena tujuan dari penelitian adalah mendapatkan data. Untuk mendapatkan data mengenai pengembangan kompetensi pedagogik guru anak berbakat maka dipergunakan beberapa teknik pengumpulan data, yaitu wawancara, observasi, studi dokumentasi, dan triangulasi data.

\section{HASIL PENELITIAN DAN PEMBAHASAN}

Kompetensi pedagogik guru sangat penting bagi seorang pendidik, karena akan menentukan tingkat keberhasilan proses dan hasil belajar siswa. Hal pertama yang peneliti ingin ketahui adalah bagaimana kompetensi pedagogis guru dan anak gifted? Berdasarkan hal ini, peneliti akan memeriksa dengan mewawancarai 2 guru di SD gifted cugenang cianjur jawa barat.
Penelitian ini berlangsung selama 2 bulan dengan mempertimbangkan. peneliti menguraikan temuan di lapangan mengenai: 1) profil pelaksanaan kompetensi pedagogik guru anak gifted yang diungkap dari 10 aspek kompetensi pedagogik itu sendiri yaitu, berdasarkan cara guru a) menguasai karakteristik peserta didik dari aspek fisik, moral, spiritual, sosial kultural, emosional, dan intelektual; b) menguasai teori belajar dan prinsip-prinsip pembelajaran yang mendidik; c) mengembangkan kurikulum yang terikat dengan mata pelajaran yang diampu; d) menyelenggarakan pembelajaran yang mendidik; e) memanfaatkan teknologi informasi dan komunikasi untuk kepentingan pembelajaran; f) memfasilitasi pengembangan potensi peserta didik untuk mengaktualisasikan berbagai potensi yang dimiliki; g) berkomunikasi secara efektif, empatik, dan santun dengan peserta didik; h) menyelenggarakan penilaian dan evaluasi proses dan hasil belajar; i) memanfaatkan hasil penilaian dan evaluasi untuk kepentingan pembelajaran; j) melakukan tindakan reflektif untuk peningkatan kualitas pendidikan. 2) kendala yang dihadapi dalam pelaksanaan kompetensi pedagogic guru anak gifted yang dilihat dari keluhan, kesulitan, keterbatasan dan masalah yang dihadapi dalam pelaksanaan kompetensi pedagogik guru anak berbakat di Cugenang Gifted School Tingkat Sekolah Dasar dan 3) penyusunan rumusan program 
Tri sundari, Babang Robandi, Yuyus Suherman : Pengembangan ...

pengembangan kompetensi pedagogic guru anak gifted di Cugenang Gifted School Tingkat Sekolah Dasar.

\section{Pembahasan}

Peran guru sebagai salah satu elemen staf pengajar dan sumber daya pendidikan, serta sumber belajar yang paling penting, memiliki tugas, fungsi, peran dan tanggung jawab untuk membimbing siswa mengajar dan melatih. Peran kompetensi pedagogik guru sangat penting dalam mencapai hasil pencapaian yang baik. Karena itu, seorang guru.

Kompetensi guru dapat diartikan sebagai kebulatan pengetahuan, keterampilan dan sikap yang ditampilkan dalam bentuk perilaku cerdas dan bertanggung jawab yang dimiliki oleh seorang guru dalam menjalankan profesinya. Jelas bahwa seorang guru dituntut untuk memiliki kemampuan kompetensi dalam pengetahuannya, kemampuan untuk menguasai mata pelajaran, kemampuan untuk berinteraksi sosial dengan sesama siswa dan dengan sesama guru dan kepala sekolah, bahkan dengan masyarakat yang lebih luas. Untuk mewujudkan siswa yang memiliki abad ke-21 keterampilan, guru harus memahami dan memiliki kompetensi ini. Ada 3 aspek penting dalam kompetensi abad ke-21 ini, yaitu: Karakter, karakter yang dimaksud dalam kompetensi abad ke-21 terdiri dari karakter yang bermoral (jujur, dapat dipercaya, sopan, dll) dan ciri- ciri kinerja (kerja keras, tanggung jawab, disiplin, gigih, dll). Keterampilan, keterampilan yang perlu dimiliki oleh guru saat ini untuk berurusan dengan siswa abad ke-21 termasuk kritis, kreatif, kolaboratif dan komunikatif. Literasi, kompetensi abad ke-21 mengharuskan guru untuk melek huruf di berbagai bidang. Setidaknya mampu menguasai literasi dasar seperti literasi keuangan, literasi digital, literasi sains, kewarganegaraan dan budaya

\section{SIMPULAN}

Pengembangan kompetensi pedagogik guru anak berbakat belum menjadi perhatian, sehingga perlu untuk merancang program khusus untuk guru anak berbakat. dalam pengembangan kompetensi pedagogik. Pengembangan kompetensi telah dibuat disesuaikan dengan karakteristik anak berbakat sehingga dapat dijadikan sebagai tolak ukur dalam pengembangan kompetensi pedagogik guru anak berbakat.

\section{DAFTAR RUJUKAN}

Andini, D. M \& Supardi E. 2018. Kompetensi Pedagogik Guru Terhadap Efektivitas

Pembelajaran dengan Variabel kontrol Latar Belakang Pendidikan Guru. Jurnal Pendidikan Manajemen Perkantoran, Vol. 1 No.2.

Anggara, R., \& Chotimah, U. 2012. Penerapan Lesson Study Berbasis Musyawarah Guru 
Mata Pelajaran (MGMP) terhadap Peningkatan Kompetensi Profesional Guru PKn SMP Se-Kabupaten Ogan Ilir. Jurnal Forum Sosial, 5(2), 188-197. Retrieved from http://eprints.unsri.ac.id/1421/\%5 Cnhttp://eprints.unsri.ac.id/1421/ 1/Penerapan_Lesson_Study_berb asis_MGMP_PKn.pdf

Davis, G. A., Rimm, S. B., \& Siegle, D. 2011. Education of The Gifted and Talented $\left(6^{\text {th }}\right)$. Boston: Pearson.

Hairunnisyah Sahidu, et al. 2013. Penyuluhan tentang Lesson Study (LS) untuk Meningkatkan Kompetensi Pedagogik GuruGuru di MAN 2 Mataram. Journal of Chemical Information and Modeling, 53(9), 1689-1699. https://doi.org/10.1017/CBO9781 107415324.004

Hidayat, Rahmat. 2013. Pedagogi Kritis: Sejarah, Perkembangan dan Pemikiran. Jakarata: Rajawali Pers.

Jhon M. Echools dan Hasan Shadily. 1984. Kamus Inggris-Indonesia. Jakarta: Gramedia.

Khamdan, dkk. 2012. Strategi Pembelajaran Pendidikan Agama Islam di sekolah (Teori, Metodelogi, dan implementasi). Yogyakarta: Idea Press.

Landvogt, J. 2001. Affecting eternity: Teaching for talent development. Roeper Review, 23(4), 190-196. https://doi.org/10.1080/02783190 109554097

Mills, C. J. 2003. Characteristics of effective teachers of gifted students: Teacher background and personality styles of students. Gifted Child Quarterly, 47(4), 272-281.

https://doi.org/10.1177/00169862 0304700404

Munandar, Utami. 2009. Pengembangan Kreativitas Anak Berbakat. Jakarta: Rineka Cipta

Rogers, Karen B. 2014. Pendidikan Anak-anak Berbakat dan Bertalenta. Jakarta: Indeks.

Rusman. $2010 \quad$ Model-model Pembelajaran Mengembangkan Profesionalisme Guru. Jakarta: PT Raja Grafindo

Santrock, John W. 2010. Psikologi Pendidikan, Edisi Kedua. Terjemahan Tri Wibowo B. S Educational Psychology, $2^{\text {nd }}$ Edition. Cetakan Ke-3. Jakarta: Prenada Media Group.

Subadi, T. 2013. Lesson Study Sebagai Inovasi Pendidikan. Surakarta: Kafilah Publikasi

Supranoto, H. 2015. Penerapan Lesson Study Dalam Meningkatkan Kompetensi Pedagogi Guru Sma Bina Mulya Gadingrejo Tahun Pelajaran 2015/2016. Jurnal Pendidikan Ekonomi, 3(2), 2128.

https://doi.org/10.24127/ja.v3i2. 330

Zhang, Z. 2017. Gifted education in China. Cogent Education, 4(1), 1-12.

https://doi.org/10.1080/2331186 X.2017.1364881 